\title{
A Social Approach to Students' Viewpoints About the System of Entering Tertiary Education Based on a Research Carried out in Greece (2012-2013)
}

\author{
Gogou Lela ${ }^{1}$, Kalerante Evaggelia ${ }^{2}$ \\ ${ }^{1}$ University of Thrace \\ ${ }^{2}$ University of W. Macedonia
}

Email address:

thkritikos@yahoo.gr (G. Lela), ekalerante@yahoo.gr (K. Evaggelia)

\section{To cite this article:}

Gogou Lela, Kalerante Evaggelia. A Social Approach to Students' Viewpoints About the System of Entering Tertiary Education Based on a Research Carried out in Greece (2012-2013). Science Journal of Education. Vol. 3, No. 2, 2015, pp. 22-29.

doi: $10.11648 /$ j.sjedu.20150302.12

\begin{abstract}
The present paper illustrates the research and findings based on Senior High School undergraduates' viewpoints about university exams. The research was carried out during the economic crisis in the school year 2012-2013. It was carried out in the $2^{\text {nd }}$ Educational Region of Attica using semi-structured interviews to a particular sample of students. The sample was comprised according to the snowball method. Social subjects', namely undergraduates, discourse was the focal point in order to highlight issues related to functionality or dysfunctionality of the examinations system, its effectiveness or lack of it, the manner by which these individuals perceive their presence in the educational environment as well as their educational and professional objectives. Interest is centered round studying students' viewpoints about school, issues about juvenile culture, reinforcing or rejecting educational objectives and issues related to the current economic crisis in Greece (MEMORANDUM), which is experienced both in family and school environment. According to the findings, the current examination process to enter Upper Educational Institutes in the country is regarded by students as ineffective and is apparently disapproved. An assessment is suggested focusing on Faculties and Departments having previously been selected by them. Furthermore, examinations should only take place in the particular faculties. According to the undergraduates, tutorials are necessary to enter universities whereas other issues make the school institution difficult to operate properly.
\end{abstract}

Keywords: Access to Tertiary Education, Offered School Knowledge, Subject, Educational-Professional Objectives, Operation of School Institution, Meaning

\section{Introduction}

Senior High School undergraduate students' viewpoints about the examination system for universities are the focal point of the present research. The issue of attending the university has been a matter of consideration of the Greek educational policy as it can be seen in the legislative reforms. They concentrate mainly on subjects selected by students for their examinations and on fields grouping which is part of various faculties. In this sense, certain selected subjects are examined for each field. Other considerations tied to educational reforms are the number of candidates which should be accepted in the faculties and, in particular, issues about re-examining subjects or the content of them.

Overall, the Greek educational system is based on examinations which are conducted in the Senior High School.
More specifically, undergraduates sit the Panhellenic Examination in which the topics examined are common for everyone depending on the field chosen, namely classic studies, economic faculties, exact sciences or medicine. They are classified on the basis of the collected total score. They also apply for the faculties of their preference. Yet, insufficient scores to enter their preferred faculties is a major issue. In other words, if the total score is not sufficient to enter a specific faculty they may enter another one which was chosen but was not included in their top preferences. This way, their entering the University is secured since this is regarded as both a personal and family objective. This is noteworthy of the peculiarity of the Greek family who pursue their offspring entering Tertiary Education in any way. This is the case during a period when extensive discourse is held about a different type of examinations to enter universities. 
Furthermore, viewpoints about separating graduation examinations from university examinations have been articulated. Thus, it was estimated that a research to depict the undergraduates' viewpoints would be of special interest.

The research was carried out during a period of deep economic crisis for Greece 1. Greek families experience income curtailment or unemployment among its members. As a result, deregulations or modifications of educational and professional objectives of its members are a reality. At the same time, there is intense dialogue about a different model of examination according to which selection of students will be carried out within the faculties which have been previously selected by them. Data collection was based on semi-structured interviews to students. Meanwhile, they were provided the opportunity to speak out and narrate their experiences and articulate their viewpoints about the specific matter. Their discourse composition depicts the considerations of interaction fields through their realization that current choices are based on multiple factors which are present and active in their everyday life.

The target- group helped the researchers understand the meaning given by the students to the social and educational everyday reality. Their viewpoints reflect issues of school structure and operation while there is an explicit or implicit evaluation of the educational work and the carriers' role. Their subjective arguments are understood and interpreted within a broader framework tied to the juvenile culture in terms of time and space.

\section{Methodology}

The initial research hypothesis was how these social subjects interpret the formed educational situation, their considerations about the examination system and the exams to enter University which are determinant to their future professional course. The Greek society focuses on their offspring's education in the sense that a University degree is deemed necessary. As a result, families invest on this venture, in terms of time and money, to reinforce the youngsters' choices for Tertiary Education. At the time of conducting this research, a discussion was underway relevant to the effectiveness or not of the examination system. It was estimated that the students' discourse was absent and this was conductive to conducting the research.

The research2 was carried out throughout 2012-2013 to twenty (20) Senior High School undergraduate students. Focus was placed on this particular population as it was assumed that their discourse would depict their entire educational experience. Moreover, they would be able to evaluate the general educational conditions. At the same time, the fact that they prepare for their exams and their entrance to

\footnotetext{
1 See (indicatively) about the existing economic crisis in Greece with emphasis on the effects on economic, social, political and cultural levels (Mazower, 1991; Tsakalotos \& Laskos, 2013; Sotiropoulos, 2014).

2 See (indicatively) about the qualitative analysis method and especially about the sample and semi-structured interviews (Creswell, 2012; Yin, 2010; Merriam, 2009).
}

another educational area tied to their career would depict broader considerations about the formed political, social and economic situation. The snowball method was used to form the sample in the $2^{\text {nd }}$ Educational Region of Attica. The snowball method is applied when there is need for a population to meet the research requirements in short time (Tracy, 2013). In this case, shift was made from one student to the other after having secured their responding to the research, their collaboration and their representing a special group in terms of gender, family's educational capital and school performance. There had been collaboration with the teachers prior to the research so that the formed sample could meet the requirements set. The specific area is representative of the overall character of schools in Greece with students from all socio-economic, cultural and national backgrounds. Students' performance at the examinations is equal to that of other students across the country. The creation of the sample was also based on the collaboration with teachers of the afore-mentioned educational area and criteria about gender, social class, national identity and school performance were taken into account3.

The focal point of the research is students' subjective articulations. Hence, semi-structured interview were deemed necessary. Interest was placed on profoundly studying the students' attitudes and viewpoints by approaching special issues on how they associate present with future and education with career, especially within a period of economic crisis and insecurity. The semi-structured interview provided the possibility to analyze notions, investigate conditions deriving from their discourse during the interview. Following the discourse analysis (Gee, 2014), the total of interviews were collected and classified according to the corresponding thematic units and similarities and differences were defined. This way, the discourse could be analyzed and the students' interests, tied to the broader juvenile culture, could be spotted. Discourse analysis provides the opportunity to approach their viewpoints, elevate the ideological context, define the emotional state and enable the overall image of social and political subjects. Students' answers were recorded upon their consent. In addition, emphasis was placed on creating functional relationships with the students. As a result, the researcher-subject communication corresponds to the objective of analytical approach of issues which are included in their discourse. It was interesting to hear about the manner by which students are assessed in schools, their viewpoints about the examinations system, their school life, their expectations about school as well as their educational and professional objectives. Issues that link juvenile culture to the students' presence in schools where their future is shaped through their choices were highlighted4.

The time period when the research was carried out was

\footnotetext{
3 See (indicatively) considerations about qualitative research, objectives and methodology with emphasis on the Greek issues (Gogou, 2010).

4 See (indicatively) issues of juvenile culture emphasizing the adoption of attitudes and behavior corresponding to broader interpretations about the perception of juvenile groups as part of a social behavior model (Brake,2014; Corsaro, 2014; Warikoo, 2011)
} 
tied to the economic crisis and the developments of the crisis in the social, political and cultural domains. It was assumed that students' answers and considerations would reflect broader considerations from various domains to which students implicitly or explicitly belong. It should be taken into account that during this time period students experience cost curtailments in education. Thus, material infrastructure is limited in schools and, at the same time, a policy of abolishing or merging schools or reduction of teachers due to abolishing of cognitive objects is implemented5.

\section{Discourse Analysis}

The students' discourse analysis shows that it is necessary to adopt a different examination model to access Tertiary Education. The fact that the existing model of assessment is favorable only to the "best" students, namely those ones that meet the requirements of the present system, which in turn, rejects all others who wish to attend Tertiary Education, is also highlighted. A number of the students actually question the manner of preparation throughout Senior High School to access University. Despite the fact that they are incensed at the present educational system of entering University, they point out that a system of assessing them in certain subjects is necessary to ensure a high level of performance.

"Yes, I believe that they are necessary, for every child, to belong to a level".

"There could be state exams for three consecutive years with a mean score. If something happens one year and we have... some emotional burden or something like that and fail, we will not miss the chance".

"I believe that...state exams are a good way to select candidates for universities, I believe that this is a good way... However, children are affected throughout the school year, that is... children get mad throughout the year due to anxiety but...I believe it is an unimpeachable institution and I believe that...it is difficult to find another system, a better system. It has been in force for many years. Before that there were the thematic fields, not it's the State exams, meaning that it has proved to be a good system. Individuals who graduate from Greek universities or Polytechnic schools have a very good level of knowledge... Besides, they could have not met the requirements of universities if State exams had not existed. Do you understand my reasoning or am I speaking strangely?"

Some students regard assessment as a prerequisite to access University. Furthermore, they demand to be given the possibility to improve their performance throughout the three years of attending Senior High School by having a better preparation in the different subjects. More special issues about the system of examination are of special interest. They

5 See (indicatively) about the effects on education of lower social strata and the formed worsening of social inequality (Kalerante, 2015). primarily underline the fact that they do not have the possibility to attend the faculty of their preference since, according to the current legislation. They can also apply for many different faculties which are far from their interests. They have to apply for them in order to access Universities.

"I suggest that...everyone wants to engage themselves with a specific thing. To my mind, each student could choose this particular thing, the faculty of their preference. They could enter the faculty and continue up to the end. OK, a weak student could not possibly apply for Medical School. Yet, if one wants to study Medicine one must want this very much and try hard to achieve it. I strongly believe that it is a mistake to apply for many schools and if you pass... you pass. Something like that."

"I believe that there should be a mean score from the three Senior High School grades...We should sit for the State exams for three years or something the like and not rely merely on one year which is determinant to our future. Things could change a little."

"I believe that students would have anxiety only in the first year. Afterwards, during the second and third year things could be easier as students would have the experience of how the system is like... what they should write and how things would be in general."

Some students believe that the process of preparing for Universities deprives them of the possibility to entertainment during adolescence. When the school day is over, they mostly focus on attending group or individual tutorials as well as doing assignments in order to meet the examinations requirements. In this sense, the time period they cover is emotionally extremely difficult for them, since their success and personal progress is identified to their success in the State exams. The necessity to form a different assessment system taking into consideration all teenagers' needs without being a source of anxiety and prevention of any extracurricular activity is particularly underlined.

"The negative thing is that students have too much anxiety and instead of performing well in the exams they finally do not due to anxiety.... Due to being overloaded with anxiety by their surrounding environment since they are aware of the importance of their performance and they are afraid of making mistakes.... Actually, it is not quite clear for someone to understand from a single paper what a student worth or not, namely the good qualities of the student... and what one can achieve."

"Another issue for students is that they are assessed in subjects unrelated to the faculty of their preference. They apparently transfer the issue of choice directly to universities. In other words, the student should choose the faculty he / she prefers and be assessed in the University."

"I suggest that there should be a system in which students would feel less anxiety, perhaps by being examined in 
subjects relevant to their faculty and not being overloaded with subjects that they will never be engaged again in the future, but they are merely a source of further anxiety."

Besides the previous outcome of irrational operation of the educational system, a second irrational issue is that of preparing for the examinations. Attending school subjects is not enough for someone to get prepared for University exams. Students choose to attend tutorials so as to boost their performance. According to research findings they go to school just because they go to school as there is no access to University without it. They refer to the fact that their attention focuses on the subjects to be examined to access Tertiary Education. Therefore, they attend either group or individual tutorials, for which they have to pay extra, in order to prepare themselves in certain subjects.

"Hmmm... it is necessary in some subjects, like the ones I wish to engage with... due to the direction I have chosen...tutorials are necessary, because they assist me to score a good mean and... essentially score higher in the State exams next year when... and this is what I am going to do, I will continue attending tutorials in August to help myself and to achieve the score which is required from my faculty."

"And then...the tutorials started... and the teachers tried, somehow, to fill all the gaps... OK, they did something, but... they are gaps anyway."

"Yes, tutorials, there should be some help...but there are children who do not attend tutorials, they are almost excluded from the process of examinations. This is the bad thing."

"OK, let's say....in theoretical orientation, they are more than necessary in comparison to other orientations. Yet, school is not supportive, neither school..... the books."

"My teacher and I did the content of the book, but we are in advance. We actually do not engage with exercises, we are not in the same chapter as in school. We move forward to the next unit and I know how to perform in the classroom."

"I believe it is difficult for someone to achieve one's objectives without extra-curricular support. The way things have turned out to be, state exams require a higher level than that offered by the school."

"Yes, this... this is achieved with group or individual tutorials in the $3^{\text {rd }}$ grade of Senior High School, because work in schools is off-hand, especially in the subjects of the orientation $\mathrm{hmm}$... because the content of the material should be covered in short time and this is not done properly in the subjects of orientation. Therefore, students are mostly based on the tutorials."

"You can sit the State exams with a lot of personal work and effort and without tutorials. I personally believe that if my objective were too high I could not achieve it without tutorials. I would just be happy to enter a lower faculty, but I believe no one deserves that."

\section{"[...] No, just for prevention....."}

Another issue of consideration is that in Senior High School the course of subjects is not naturally unfolded from one grade to the other as there is a gap between the various grades. The reality is that there is neither cross-curricular continuation in the subjects nor a climax regarding the content of subjects from one grade to the other. This way, any gaps occurring in the $2^{\text {nd }}$ and $3^{\text {rd }}$ grade are covered with group tutorials or individual tutorials at home. According to the interviews, neither students nor their parents are obsessed with tutorials. It is the operation of the school institution, the organization of material as well as teaching methodology regarding access to Tertiary Education that are under question. Students do not feel confident and secure in case they rely solely on the school knowledge which is offered. They seek after more reinforcement to their studying and find it in tutorials.

"I am good, yes,... but because...actually Physics, I attended tutorials last year hmm... Physics, and because there was a huge gap between Physics of $3^{\text {rd }}$ grade Junior High School and $1^{\text {st }}$ grade Senior High School and respectively the $2^{\text {nd }}$ grade which is a continuation of the $1^{\text {st }}$ grade hmm....I had to attend tutorials in Physics because I perceived the difference between the two grades."

According to students' remarks, tutorials are not carried out only throughout the school year but even during summer holidays. The "well" prepared student is the one who attends tutorials during summer holidays. It is observed that students do not have free time to engage with personal interests, socialize and enjoy their youth. Their time during summer is organized as informal school time in which personal moments are missing. Tutorials are unfortunately a common practice not only in the Senior High School but also in the Junior High School. Therefore, the subjects' discourse shows that students, as adolescents, lack any possibility to enjoy their youth and, consequently, vindicate their rights as adolescents under political terms.

"Hmm...they are necessary for some subjects, like the ones I want to... actually follow...in the orientation I have chosen hmm...they were necessary, because they supported me to score a good mean and...actually score high in the State next year when... and that is what I am going to do. I will continue in August; I will attend some tutorials to support myself more in order to achieve the high score required by my faculty."

"Hmm...I commenced individual tutorials in the $1^{\text {st }}$ grade of Senior High School. I had never done before. I only attended for one year hmm... not actually tutorials, but rather some support in Mathematics with a teacher who lived in the floor under our flat." 
"Yes, I did in the Junior High School....I actually attended tutorials up to the $2^{\text {nd }}$ grade Senior High School."

Students' families hold a crucial role to anything relevant to school performance and professional orientation regarding their offspring and they support financially their children's tutorials. Parents follow their children's development in the educational environment and interfere in order to increase the possibility for their children to enter University. The Greek family functions in a peculiar way by offering protection to its members and providing care to their everyday life. In this sense, success or failure to enter Tertiary Education is not merely students but also parents' concern.

"Hmm...when I attended the $1^{\text {st }}$ grade of Senior High School my parents made me attend tutorials as they told me that I would do Ancient Greek for sure, and Essay and afterwards...Mathematics and...hmm... when I did the School Professional Orientation test and I hear about the gap in Physics of $3^{\text {rd }}$ grade Senior High School [...]"

"No. Hmm.... No, it was my parents' wish to attend tutorials. They said that I should attend tutorials and I did it. That's all."

\section{“[...] Parents' pressure [...]"}

When relying on tutorials profound knowledge is not sought after. On the contrary, parents and students focus on "instrumental knowledge" which is tied to obtaining good scores. The aim is to achieve high scores in the state exams. In depth knowledge is not developed, cognitive horizons are not expanded and interests are not cultivated. School operates as a preparation centre for exams and, according to students' words, in a particularly lacking and insufficient manner since the majority of students attend group or individual tutorials to acquire supplementary knowledge.

"I would not score... eighteen or nineteen. I think I would have lower scores like fourteen, fifteen or something like that."

Teachers' assessment is another issue put forward by students. They regard some teachers as "inappropriate" because they are neither aware of the cognitive field nor treat students properly whereas others are found to be particularly co-operative. In terms of the current issue of teachers' assessment which is under examination by the educational policy (during carrying out this research), students' discourse analysis might contribute to a fruitful dialogue about the criteria of operating and organizing school with emphasis on the teachers' role.

"Actually, she/he did not teach at all, she asked us to say what was written in the books...because he/she knew that we attend group or individual tutorials [...]"

"Nowadays, the way in which education has been shaped, tutorial support is more than necessary. Not all teachers make the utmost of their effort. They are sure and settled down that students know because they have heard so they do not try hard. Yet, I could not say the same for my philologist who did anything he/she could for us. Her instruction was that of tutorial level. We stayed in the classroom with her even throughout breaks and she was always eager to help us."

"It is not only the gaps. Let's say I know...I do not know many teachers who do not try resulting in us having gaps. There are two or three teachers who are not able to instruct the way they should $[\ldots]$ "

"For example, the Physics teacher hmm...we did not understand most of what he/she was saying and we felt we needed some kind of tutorial. On the contrary, the Mathematics teacher explained everything clearly and there was no need...to attend tutorials."

The advantages of the selected research tools, namely extended semi-structured interviews, include the establishment of a trust and confidence climate so that all students trigger certain issues and are offered the possibility to emphasize thematic units they are interested in. students' proposals about the organization of the examinations system to enter University are of special interest. In this respect, the former parameter focused on the implementation of an examinations system to enter University and the current one is their exact proposals about the examinations system. They explicitly state that there should be a separation between graduation examinations and University examinations.

"Anyone who does not opt for University should be able to sit graduation examinations, not State examinations."

"I strongly believe that they should not exist. Another system should be in force, because...there is much anxiety among children and...I am not sure whether it is... a fair way. I believe it is, but it is not the suitable one."

"There might be...some, many examinations throughout the school year and they could sum up to a final score and there might be different kinds of tests. Thus, if you failed one test you would not be frustrated because there would be more tests. As a result, there would be a balance."

"I believe that the best thing would be to...each University should administer its own examinations and students could sit these examinations at the University. This way, there would be more justice."

Even though they are extremely busy with their exams, they provide an overall evaluation about the role of school regarding students' education. In this sense, the need for a different school in terms of organization and operation is suggested. On the basis of the interviews, the educational system reform was their major consideration, concentrating on the human being, the joys of life and the enjoyment of knowledge.

"The elimination of tutorials would be ideal for me. The 
school program could be longer and more responsible work could be done by more active teachers, especially about issues relevant to children. They should focus more on what they do and be closer to children."

Students of the sample pinpoint some differences among their school mates about receiving knowledge. However, these differences are not tied to economic, educational and social capital issues among their families. The so-called "good" student is valued in the school environment while rights and privileges are immediately acknowledged."

"That...a strong student, with high scores, can not, say, school, in the same classroom with a student of low level scores. He/she does not deserve that, there should be hmm...each one should be rewarded for what ones has gained... for what one has achieved and according to one's effort. This is what I believe. In other words, I do not deserve to share the same place with an excellent student who scores twenty, nineteen or eighteen. This student should hmm...be rewarded for the endeavor and struggle. That is what I believe."

"Yes, I do not mean that hmm...if one is smart or not, I mean it in terms of studying, hmm.. if one feels like wanting to enter University, a certain faculty, to further one's knowledge and out of... mainly, all the sacrifices that have been done. I mean that such a student has definitely made some sacrifices. For example, I have not made any sacrifices as I hang out with my friends all day and train all day, go to the cafes or similar things. I believe that I do not stand on the same side with the student who has sacrificed all these things."

"Maybe, depending on one's effort to study. If the student decides to study hmm..and.. ok ask for advice and I believe, some notes by someone else then success is pretty sure. It depends on studying. We just attend tutorials for further help, to hmm...I mean that we are supported in our studying and understanding. But if the student is capable enough there are definitely many people who succeeded in this way."

Some students point to the economic crisis effects on their families without excluding peers from different socioeconomic and cultural or national backgrounds. The specific students refer to the current economic crisis; yet, not profoundly. Their focus is primarily placed on the lacking economic capital and restricted access to the labor market.

"No, I generally do not attend tutorials. Ok, it is the financial situation, nowadays, but...generally I do not."

"Hmm...financial reasons mainly, but I never thought of individual tutorials. Group tutorials were my only choice."

The examinations system to enter University is questioned by some students who underline competition as the negative key factor of the system. Lack of transparency in processes and institutional dysfunction are mentioned but not under political terms.

"I regard the system sort of unfair because some children certainly $\mathrm{hmm}$...because it is not possible to assess...a person to be assessed within three hours for the whole amount of work which has been done. The system is very competitive as one tries to score higher than the others. Furthermore, it is unfair because many times there are students who know the content of questions because they know someone in the examination committee $[\ldots]$ "

\section{Conclusions}

The Greek family perceives education as an investment even during the economic crisis period. The favorable sociocultural strata can afford to support their children by providing either group or individual tutorials to them. Long term attendance is a reality in Greece. Greek families concentrate more on tertiary sector which includes services and less on secondary and primary sectors. The limited development of agricultural and industrial sectors is tied to multiple public services and irrational operation of the political system which is dominated by a cliental model of accessing the public sector by Secondary and Tertiary Education graduates6. Despite the shrunk public sector due to cost curtailments which are conducive to limiting state services, the tertiary sector is people's first choice as the other two sectors are associated with insecurity and uncertainty within a system of confined labor rights and unemployment. According to the research findings, students rely on group or individual tutorials to accomplish their goals The family's economic background holds a crucial role because those ones of high economic capital can support financially their children's efforts to enter University and choose a career and this is more intense during the economic crisis.

Social inequality is reinforced by the applied policy to enter University. Children belonging to advantageous social strata attend highly prestigious faculties. It is them who possess the economic, educational and social capital so that they can afford to attend tutorials increasing, this way, the possibility to enter University. It should be taken into account that advantageous social strata have a dynamic interference in their offspring's education. More specifically, they manage information within an extended globalized system, clearly judge the future by evaluating the present facts and preparing their children for the labor market. During an economic crisis period it should also be taken into account the fact that this social group, except for good organization of the instrumental knowledge required to opt for University, prepare its offspring to receive further knowledge conducive to creating interests such as foreign languages, fine arts etc 7.

6 See (indicatively) about the choices of Greek families relevant to their offspring education which aspires to their integration into the tertiary field and the political association of this choice with the clientele system (Tsoukalas, 2006).

7 Within a period of economic crisis the worsening of social inequality is of special interest as it is maximized due to upper social strata providing a strong 
The present research shows that the educational system is inefficient within a crisis period. On the basis of democratic and humanistic principles it should reinforce its structures, so that students' needs are met, especially those ones of lower social strata. As a result, a loose condition has been formed conducive to marginalizing lower social strata and immigrants not having the possibility to pursue their dreams. Teachers are apparently processors without any communication between them and their students and without attempting to provide an effective education. It is important that everyone in the educational community is aware of the tutorials taking place but they do not seem to be preoccupied by this phenomenon. There is criticism on the typical and instrumental knowledge provided regarding its effectiveness as well as on the useful knowledge which is necessary to students, yet, it is not provided.

In Greece, citizens do not participate in the formation of the educational policy. Students express their proposals about the formation of the educational system, especially to enter University. A dialogue between students and teachers which would take place prior to legislation drafting would be interesting. Nowadays, reference is made to institutional crisis as democratic institutions are tested, the operation of the citizens' society could offer the possibility to commence a dialogue and would enhance processes towards a model of deliberation in which any consent, being the outcome of views exchange, would be given special attention.

It is realized by students that preparation for University is disorganizing to the young as the latter defines its life within a confined educational environment in the way it is formed; focusing on instrumental knowledge. On the basis of the students' discourse it is concluded that students do not enjoy their holidays and, consequently, there is no free time to be utilized and managed according to their interests. Moreover, they cannot live their lives as young people should do and are not given the opportunity to enjoy the age of 17 or 18 . In addition, preparing to enter University is not associated with specific professional objectives or interests. They apply for faculties which are not among their preferences because the focal point is solely success, namely to enter any faculty. At this point differences among various socio-economic and cultural environments are highlighted. Advantageous social strata hold the economic and educational capacity to support their children towards certain choices for higher education. Meanwhile, they have the opportunity to reject the Greek system and opt for higher education abroad. It is important that students think of a reformed educational system under humanistic criteria set by the scientific carriers. In this sense, they reject state exams and suggest that examinations be transferred within universities. This is an important issue which could be of primary consideration in the educational policy. During a period of economic crisis interests and personal preferences can be conducive to changing the

economic capital and better education to their offspring (McNamee \& Miller, 2009). At the same time, they reinforce conventional education provided in educational institutes with various educational capitals offered to the educated people's free time (Kalerante, 2013). economic paradigm as well as the creation of happy citizens that would contribute to economic development and social prosperity.

To recapitulate, it could be argued that, on the one hand, students of the sample ask for opportunity structures within the system by criticizing the current democratic system and, on the other hand, they lack the knowledge necessary to interpret the current conditions. Being young, they seek moments of their lives and correlate the educational system to the confinements in their personal life. Moreover, they feel entrapped within an examinations system moving them away from cognitive fields and true contact with knowledge.

Within a period of broader economic, social and political reclassifications the research findings will contribute to the broader considerations about the drafting of an examination system in which students' viewpoints would be taken into account. In other words, in the citizens' society and pressure groups a broader discourse should emerge in which students would also be included. Juvenile culture and the youngsters' right to live and be happy have been overlooked by the educational policy. They should not be continuously concentrated on acquiring infertile knowledge which is examined by a single-dimension examination system. At the same time, the research will contribute to the teachers' considerations about their role in the educational system, their relationship to students and the assessment of their work at a time when students are preparing for their exams outside the school environment. Additionally, policy makers could utilize the present findings to redefine political standpoints about education with emphasis on the students' needs and viewpoints about the redrafting of education, curricula, structure and operation of education. The present qualitative research could spark off an extended quantitative research with a specific questionnaire depicting the educational situation, the educational system in order to re-evaluate all the structures and operations of education.

\section{References}

[1] Brake, M. (2014). The Sociology of Youth Culture and Youth Subcultures. London: Routledge.

[2] Corsaro, W. (2014). The Sociology of Childhood. London: Sage.

[3] Creswell, J. (2012). Qualitative Inquiry and Research Design: Choosing Among Five Approaches. London: Sage.

[4] Gee, J. P. (2014). An Introduction to Discourse Analysis: Theory and Method. London: Routledge.

[5] Gogou, L. (2010). The understanding of social phenomena and the perspectives of social research. Athens: Grigoris.

[6] Kalerante, E. (2013). Greek Educational Policy in recessionary Times: Does liberal educational Policy take its toll on the Leisure Activities of the lower social Strata? In Cappello, G., Modi, I. \& Massimo Lo Verde, F. (2013). Mapping Leisure Across Borders. Cambridge: Cambridge Scholars Publishing, 379-389. 
[7] Kalerante, E. (2015). "The educational policy as an economic narrative through the emerging bio-political performance: conjunction between educational operation and economic systems" in: Konstantopoulou, Ch. (ed.) Social Representations: Communicative Media and Authority. Athens: Papazisi (forthcoming)

[8] Mazower, M. (1991). Greece and the Inter-War Economic Crisis. Oxford: Oxford University Press.

[9] McNamee, S. \& Miller, R. (2009). The Meritocracy Myth. USA: Rowman \& Littlefield Publishers.

[10] Merriam, S. (2009). Qualitative Research: A Guide to Design and Implementation. San Francisco: Jossey-Bass/Wiley.

[11] Tracy, S. (2013). Qualitative Research Methods: Collecting
Evidence, Crafting Analysis, Communicating Impact. USA: Wiley-Blackwell.

[12] Tsakalotos, E. \& Laskos, C. (2013). Crucible of Resistance: Greece, the Eurozone and the World Economic Crisis. London: Pluto Press.

[13] Tsoukalas, K. (2006). Dependance et reproduction. Le role social des appareils scolaires en Grece. Athens: Themelio.

[14] Sotiropoulos, D. (2014). Aftershocks: The Political Fallout of Greece's Economic Crisis. New York: World Politics Review.

[15] Warikoo, N. (2011). Balancing Acts: Youth Culture in the Global City. California: University of California Press.

[16] Yin, R. (2010). Qualitative Research from Start to Finish. New York: The Guilford Press. 